\title{
COMPUTERISED TOMOGRAPHY AFTER POSTERIOR DISLOCATION OF THE HIP
}

\author{
KJELD HOUGAARD, STEEN LINDEQUIST, LISBETH B. NIELSEN
}

From Odense University Hospital, Denmark

\begin{abstract}
We have reviewed 19 consecutive patients admitted to the Odense University Hospital after traumatic dislocation of the hip. We aimed to perform computerised tomography as soon as possible after closed reduction; this was accomplished in 15 patients. The CT scans revealed intra-articular fragments of bone in five hips, and fractures of the femoral head or acetabulum in six. In two cases the CT scans excluded fractures or intra-articular fragments which had been suspected on conventional radiography.

CT scanning is a useful diagnostic tool in traumatic dislocation of the hip; we consider that it makes an important contribution to management.
\end{abstract}

Traumatic dislocation of the hip is a severe injury and late secondary osteoarthritis may develop, despite prompt and adequate reduction (Stewart and Milford 1954; Upadhyay and Moulton 1981). Epstein (1973) reported 151 open operations for such dislocations and found loose fragments of bone within the hip of all but 13 of the patients.

It is often difficult to evaluate the condition of the femoral head and the acetabulum by conventional radiography after a severe injury to the hip. Computerised tomography (CT) can provide additional information, and we have examined a series of patients after traumatic dislocation of the hip in order to assess the value of this investigation.

\section{PATIENTS AND METHODS}

At the Odense University Hospital, 19 patients were treated for traumatic dislocation of the hip during the period between December 1983 and November 1986. All had posterior dislocation. There were 17 men and two women with an average age of 37 years (range, 17 to 74 years). All but one of the dislocations were the result of traffic accidents.

In 15 hips, closed reduction was achieved within six hours of injury. In two cases closed reduction failed and, in both, CT scanning demonstrated a loose fragment of bone in the joint. The two other hips were treated late, three days and three weeks respectively after dislocation.

K. Hougaard, MD, Senior Orthopaedic Registrar

S. Lindequist, MD, Registrar in Radiology

L. B. Nielsen, MD

Odense University Hospital, 5000 Odense C, Denmark.

Correspondence should be sent to $\mathrm{Dr} \mathrm{K}$. Hougaard.

(C) 1987 British Editorial Society of Bone and Joint Surgery 0301-620X/87/4097 \$2.00
In both of these closed reduction failed and they had open operations.

The original injury was classified radiographically, by the grading of Stewart and Milford (1954). There were four hips with simple dislocation (Grade I), nine with a fracture of the acetabular rim (Grade II), four with a more severe comminuted fracture of the acetabulum (Grade III) and two with an associated fracture of the femoral head (Grade IV).

Our aim had been to perform CT scanning as soon as possible after closed reduction. In four cases, one in Grade I and three in Grade II, this was not achieved. In the latter three cases this was because open reduction and fixation of an acetabular fracture was undertaken immediately after failure of closed reduction. The CT scan was performed between 10 and 48 hours after the injury in the other 15 cases.

\section{RESULTS}

Grade I. CT scanning of three of the four hips with apparently simple dislocations revealed a displaced fracture of the acetabular rim in one case.

Grade II. CT scanning was performed on six of the nine hips in this group. This revealed a comminuted fracture of the acetabular floor in one hip, a displaced fracture of the roof of the acetabulum in another, and a fracture of the lower part of the femoral head in a third (Figs 1 and 2). In two other hips loose fragments of bone were seen (Figs 3 and 4). In only one case in this group did the scan fail to provide additional information.

Grade III. Intra-articular fragments of bone were demonstrated in three of the four hips with Grade III dislocations. In one case the bone fragment had been suspected on plain radiographs because of an increase in joint space. 


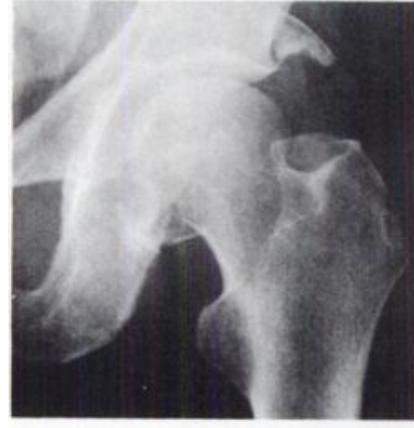

Fig. 1

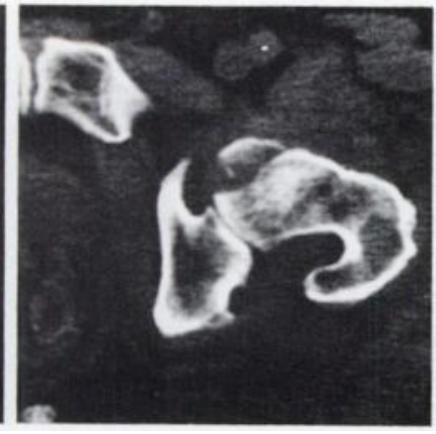

Fig. 2

This fracture-dislocation of the hip was classified on the initial radiographs as Grade II (see text). The post-reduction radiograph, seen here, shows a displaced fracture of the acetabular rim and a possible fracture of the femoral head. The CT scan clearly shows the extent of the fracture of the lower anterior part of the femoral head.

Grade IV. CT scanning demonstrated a fracture of the acetabular rim in addition to the fracture of the femoral head in both cases in this group.

In the whole series, CT scanning demonstrated loose fragments in the joint space in five hips, their size ranging from $1 \mathrm{~cm}$ by $1 \mathrm{~cm}$ to $3 \mathrm{~cm}$ by $2 \mathrm{~cm}$. As a result all were treated by open operation with removal or fixation of the fragments. In six hips CT scanning demonstrated a fracture which would otherwise have been overlooked and, as a consequence, the initial grading, based on conventional radiographs, had to be revised. In two hips, suspected fractures were excluded by the CT scans.

\section{DISCUSSION}

Stewart and Milford (1954) as well as Pipkin (1957) noted the relationship between the severity of the injury and the final outcome, while Epstein (1973) recommended open reduction and removal of intra-articular fragments of bone in certain types of dislocation. Radiographs taken soon after injury are often of poor quality, and further radiographs are frequently necessary. Smith and Loop (1976) showed that conventional tomography could provide useful information with regard to the classification of posterior dislocations of the hip, but pointed out that it could give false-negative results and that the projections used and the tomographic technique itself had to be selected with great care.

Ordway and Xeller (1984) described three cases of posterior fracture-dislocation of the hip, and showed that important information about fractures and bone fragments were not visible on conventional radiographs but could be obtained by CT scanning. Sauser et al. (1980)

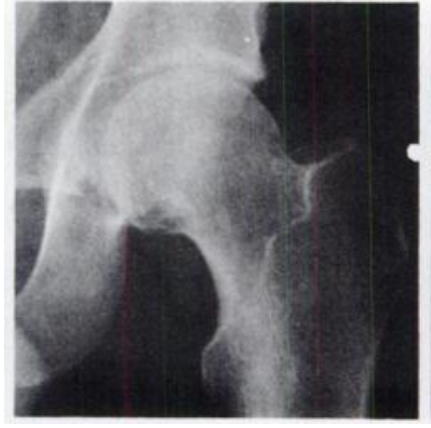

Fig. 3

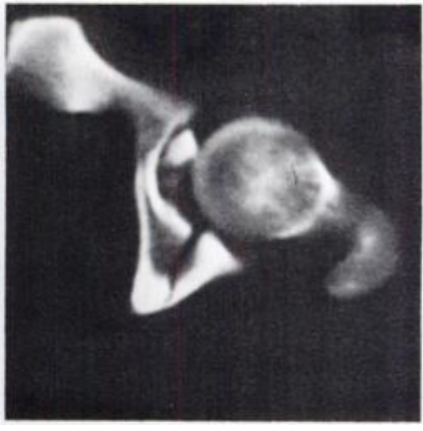

Fig. 4
The conventional radiograph after reduction shows a fracture of the acetabulum, but the CT scan also demonstrates a large intra-articular fragment.

also reported that $\mathrm{CT}$ scans provided useful information in a series of 13 patients with injuries of the hip and pelvis. The results influenced the type of treatment in four of their patients.

Our investigation has confirmed that $\mathrm{CT}$ scanning can provide useful information with regard to the classification of the severity of hip dislocations and may lead to open removal or fixation of loose fragments of bone. It is also simpler to perform than conventional tomography. On the evidence of our consecutive series of 19 patients with traumatic dislocations, we found CT scanning to be a useful tool for the accurate diagnosis of associated fractures and regard it as an essential contribution to management.

The investigation was carried out with financial support from the Danish Medical Research Council.

\section{REFERENCES}

Epstein HC. Traumatic dislocations of the hip. Clin Orthop $1973 ; 92: 116-42$.

Ordway CB, Xeller CF. Transverse computerized axial tomography of patients with posterior dislocation of the hip. $J$ Trauma 1984;24:76-9.

Pipkin G. Treatment of grade IV fracture-dislocation of the hip: a review. J Bone Joint Surg [Am] 1957;39-A:1027-42.

Sauser DD, Billimoria PE, Rouse GA, Mudge K. CT evaluation of hip trauma. AJR 1980;135:269-74.

Smith GR, Loop IW. Radiologic classification of posterior dislocations of the hip: refinements and pitfalls. Radiology 1976;119:569-74.

Stewart MJ, Milford LW. Fracture-dislocation of the hip: an end result study. J Bone Joint Surg [Am] 1954;36-A :315-42.

Upadhyay SS, Moulton A. The long-term results of traumatic posterior dislocation of the hip. J Bone Joint Surg [Br] 1981 ;63-B:548-51. 